\section{An ANOVA program for Latin square designs involving order effects}

\author{
JAMES J. ROBERGE \\ Temple University, Philadelphia, Pennsylvania 19122
}

By using a two- or three-factor Latin square design with repeated measures on two factors, the researcher can determine the variation due to order as well as that due to the treatment by order interaction. In the two-factor design, the two factors would be "treatment" and "order." In the three-factor design, the additional factor could be either a classification factor (e.g., grade level, sex, anxiety level, etc.) or another treatment.

The characteristics of these designs and/or the computational procedures are described in statistics books commonly used by behavioral scientists (e.g., Bruning \& Kintz, 1968, pp. 84-105; Lindquist, 1953, pp. 273-281, 285-288; Myers, 1972, pp. 286-300; Winer, 1971, pp. 712-717, 727-736). Gaito's (1961) comprehensive examination of the problems associated with repeated measurements designs includes a lucid discussion of the analysis of order effects by means of a two-factor Latin square design with repeated measures on both factors.

The program discussed in this paper performs an ANOVA for Latin square designs of the types described above.

Input. The job deck consists of the following cards: a problem card, a Latin square matrix format card, the Latin square matrix card(s), the label cards, a data format card, the data deck, and a last card. The problem card indicates the type of design, the number of levels for each factor, the number of groups, and the number of subjects in each group. The Latin square matrix format card is an F-type variable format card which includes the location of the numerals corresponding to the treatment levels on the accompanying Latin square matrix card(s). Each row of the Latin square matrix contains a set of numerals that specify the order of presentation of the treatment levels for a given group. In this matrix, there should be as many rows and columns as there are treatment levels. The label cards (one per factor) contain the alphanumeric labels for the factors. The data format card is an F-type variable format card which indicates the location of the raw scores on the subsequent data cards. Each of the data cards must contain the data for one subject; however, the use of more than one data card per subject is permitted. Finally, if the user wishes to terminate the program, the last card must have the word FINISH punched in Columns 1-6. On the other hand, if the user wishes to analyze another set of data, the last card is a blank card and the job deck is arranged sequentially (as described above) beginning with the problem card

Output. The printed output includes (a) the labels for the factors and (b) an analysis of variance summary table (i.e., sources of variation, sums of squares, degrees of freedom, mean squares, and $F$ ratios) which is presented in a form similar to that found in many behavioral science statistics books (e.g., Bruning \& Kirtz, 1968; Lindquist, 1953; Winer, 1971).

Computer and language. The program is written in FORTRAN IV for processing by computers in the IBM 360 (or the CDC 6000) series. Well documented, it has variable names that are mnemonic, and correspond to the verbiage used in the computational steps outlined by Bruning and Kintz (1968, pp. 84-105), to facilitate modification by users.

Restrictions. The program has the following limitations: (a) the design can have either two or three factors with repeated measures on two of the factors, (b) each factor can have a maximum of 10 levels, (c) the number of levels must be the same for the two repeated measures factors, and (d) there must be an equal number of observations in each cell.

Availability. Copies of this paper, test data, and a source listing, which includes printed output for sample problems for two- and three-factor experimental designs, may be obtained without charge by writing to James J. Roberge, Temple University, Department of Educational Psychology, Philadelphia, Pennsylvania 19122.

\section{REFERENCES}

Bruning, J. L., \& Kintz, B. L. Computational handbook of statistics. Glenview, Ill.: Scott, Foresman, 1968.

Gaito, J. Repeated measurements designs and counterbalancing. Psychological Bulletin, 1961, 58, 46-54.

Lindquist, E. F. Design and analysis of experiments in psych. ology and education. Boston: Houghton Mifflin, 1953. Myers, J. L. Fundamentals of experimental design (2nd ed.)
Boston: Allyn \& Bacon, 1972 .

Winer, B. J. Statistical principles in experimental design (2nd ed.) New York: MeGraw-Hill, 1971 